\title{
Tolerability and safety of weekly primaquine against relapse of Plasmodium vivax in Cambodians with glucose-6-phosphate dehydrogenase deficiency
}

Sim Kheng ${ }^{1}$, Sinoun Muth ${ }^{1}$, Walter R. J. Taylor ${ }^{1,2,3^{*}}$, Narann Tops ${ }^{4}$, Khem Kosal ${ }^{5}$, Khon Sothea ${ }^{5}$, Phum Souy ${ }^{6}$, Saorin Kim, Chuor Meng Char ${ }^{1}$, Chan Vanna ${ }^{8}$, Po Ly ${ }^{1}$, Pascal Ringwald ${ }^{9}$, Virak Khieu ${ }^{1}$, Alexandra Kerleguer ${ }^{7}$, Pety Tor ${ }^{7}$, John K. Baird ${ }^{10,11}$, Steven Bjorge ${ }^{4}$, Didier Menard ${ }^{7}$ and Eva Christophel ${ }^{12}$

\begin{abstract}
Background: Primaquine is used to prevent Plasmodium vivax relapse; however, it is not implemented in many malaria-endemic countries, including Cambodia, for fear of precipitating primaquine-induced acute haemolytic anaemia in patients with glucose-6-phosphate dehydrogenase deficiency (G6PDd). Reluctance to use primaquine is reinforced by a lack of quality safety data. This study was conducted to assess the tolerability of a primaquine regimen in Cambodian severely deficient G6PD variants to ascertain whether a weekly primaquine could be given without testing for G6PDd.
\end{abstract}

Methods: From January 2013 to January 2014, Cambodians with acute vivax malaria were treated with dihydroartemisinin/piperaquine on days (D) 0, 1 and 2 with weekly doses of primaquine $0.75 \mathrm{mg} / \mathrm{kg}$ for 8 weeks (starting on D0, last dose on D49), and followed until D56. Participants' G6PD status was confirmed by G6PD genotype and measured G6PD activity. The primary outcome was treatment completion without primaquine toxicity defined as any one of: (1) severe anaemia (haemoglobin $[\mathrm{Hb}]<7 \mathrm{~g} / \mathrm{dL}$ ), (2) a $>25 \%$ fractional fall in $\mathrm{Hb}$ from D0, (3) the need for a blood transfusion, (4) haemoglobinuria, (5) acute kidney injury (an increase in baseline serum creatinine $>50 \%$ ) or (6) methaemoglobinaemia $>20 \%$.

Results: We enrolled 75 patients with a median age of 24 years (range 5-63); 63 patients (84 \%) were male. Eighteen patients were G6PDd (17/18 had the Viangchan variant) and had D0 G6PD activity ranging from 0.1 to 1.5 $\mathrm{U} / \mathrm{g} \mathrm{Hb}$ (median $0.85 \mathrm{U} / \mathrm{g} \mathrm{Hb}$ ). In the 57 patients with normal G6PD (G6PDn), D0 G6PD activity ranged from 6.9 to $18.5 \mathrm{U} / \mathrm{g} \mathrm{Hb}$ (median $12 \mathrm{U} / \mathrm{g} \mathrm{Hb}$ ). Median D0 Hb concentrations were similar ( $P=0.46$ ) between G6PDd $(13 \mathrm{~g} / \mathrm{dL}$, range 9.6-16) and G6PDn (13.5 g/dL, range 9-16.3) and reached a nadir on D2 in both groups: $10.8 \mathrm{~g} / \mathrm{dL}(8.2-15.3)$ versus $12.4 \mathrm{~g} / \mathrm{dL}(8.8-15.2)(P=0.006)$, respectively. By D7, five G6PDd patients (27.7 \%) had a $>25 \%$ fall in Hb, compared to 0 G6PDn patients ( $P=0.00049$ ). One of these G6PDd patients required a blood transfusion (D0-D5 Hb, $10.0-7.2 \mathrm{~g} / \mathrm{dL}$ ). No patients developed severe anaemia, haemoglobinuria, a methaemoglobin concentration $>4.9 \%$, or acute kidney injury.

(Continued on next page)

\footnotetext{
* Correspondence: bob@tropmedres.ac

${ }^{1}$ National Center for Parasitology, Entomology and Malaria Control, Phnom

Penh, Cambodia

${ }^{2}$ Service de Médecine Tropicale et Humanitaire, Hôpitaux Universitaires de

Genève, Geneva, Switzerland

Full list of author information is available at the end of the article
} 
(Continued from previous page)

Conclusions: Vivax-infected G6PDd Cambodian patients demonstrated significant, mostly transient, falls in $\mathrm{Hb}$ and one received a blood transfusion. Weekly primaquine in G6PDd patients mandates medical supervision and pre-treatment screening for G6PD status. The feasibility of implementing a package of G6PDd testing and supervised primaquine should be explored.

Trial registration: The trial was registered on 3/1/2013 and the registration number is ACTRN12613000003774.

\section{Background}

The malaria parasite Plasmodium vivax causes an acute symptomatic blood-stage infection and characteristically has a liver stage of dormant parasites, called hypnozoites. Weeks to months later, these hypnozoites awaken to cause renewed blood infections, called relapses. Although considered a benign infection, acute vivax can result in severe disease and death in $\sim 2 \%$ of hospitalised patients $[1,2]$. Treatment is further challenged by the increasing prevalence of vivax resistance to the commonly used chloroquine [1, 3].

Treatment to eliminate the hypnozoites is also challenging for several reasons. Most $P$. vivax strains in SouthEast Asia (e.g. Chesson strain from New Guinea) relapse early and frequently, typically within 3 weeks, and cause a median of 5-6 relapses/person-year [4]. Primaquine is the only licensed drug for eliminating the hypnozoites and high doses $(0.5 \mathrm{mg} / \mathrm{kg} /$ day for 14 days) are needed for strains from South-East Asia [5-7]. Mutations in the gene encoding for the cytochrome P450 2D6 enzyme may result in fewer active oxidative metabolites and compromise the anti-relapse efficacy of primaquine [8]. In patients with the X-linked erythrocyte enzyme disorder glucose-6phosphate dehydrogenase deficiency (G6PDd), primaquine causes dose-dependent acute haemolytic anaemia (AHA) that is greater in the more severe deficient G6PD variants; AHA can be potentially life threatening but primaquinerelated deaths are very rare [9-15]. This toxicity is a significant public health concern because G6PDd affects approximately 400 million people who live mostly in malaria-endemic countries where the median G6PDd allele prevalence is $8 \%$ [16]. Testing for G6PDd is not performed in the majority of malaria-endemic countries and this effectively blocks the use of primaquine.

In a pioneering report in 1960, Alving and colleagues experimentally challenged African Americans with G6PDd $\mathrm{A}^{-}$with the Chesson strain of $P$. vivax and successfully treated them against relapse using a single weekly dose of $0.75 \mathrm{mg} / \mathrm{kg}$ (45 mg) of primaquine for eight weeks [17]. This regimen was well tolerated and produced only minor fractional drops in haemoglobin (Hb) [7 \% versus day (D)0] compared to the steeper drops (35-50\% versus D0) in the same patients given daily primaquine $[0.5 \mathrm{mg} / \mathrm{kg}(30 \mathrm{mg}) \times 14$ days $]$. This regimen came to be viewed as not only a safe anti- relapse therapy for G6PDd patients, but also as a therapeutic option where G6PD status was unknown. However, in 1960, few understood the great genotypic and phenotypic variation in G6PDd and their differing susceptibilities to primaquine-induced AHA and, in 1981, Clyde pointed out the dangers of indiscriminate primaquine use in countries with severe G6PDd variants [18].

Cambodia has a G6PDd allele prevalence of $14 \%$ and the Viangchan variant accounts for $90 \%$ of all variants. The median G6PD enzyme activity is $0.8 \mathrm{U} / \mathrm{gHb}, \sim 7 \%$ of the median population value of $12 \mathrm{U} / \mathrm{gHb}[19,20]$, making Viangchan a mostly class II G6PDd variant (i.e. 1 to $<10 \%$ of the population median [21]). When tested in fit and healthy G6PDd Cambodian airmen for 14 days, $15 \mathrm{mg}$ of daily primaquine (half the Chesson strain dose) was tolerated despite causing a mean fall in haematocrit of $9 \%(\sim 3 \mathrm{~g} / \mathrm{dL} \mathrm{Hb})$ from $43 \%$ to $34 \%$ on D7, representing a mean fractional drop of $21 \%$ compared to day 0; two men had D7 haematocrits of 26 and $28 \%$ [22]. Older Cambodian physicians report treating patients for apparent primaquine-induced AHA and acute renal failure, some of whom died. Although there is no documentation of this clinical experience, the fear of primaquine toxicity persists and is the main reason why primaquine is not used in Cambodia.

Given this fear and the paucity of data on $0.75 \mathrm{mg} / \mathrm{kg}$ of weekly primaquine, we assessed the tolerability to this primaquine regimen in severely deficient, Cambodian G6PD variants to ascertain whether weekly primaquine could be given without testing for G6PDd.

\section{Methods}

\section{Trial design, study site and ethics}

From January 2013 to January 2014, this open parallel clinical trial in G6PDd and G6PDn vivax-infected patients was conducted at Pailin referral hospital, Pailin (Cambodian Thai border), Anlong Veng referral hospital, Anlong Venh, Oddar Meanchey (north-west Cambodia), and Pramoy health centre, Veal Veng, Pursat (west Cambodia). Ethical approvals were obtained from the National Ethical Committee for Health Research of the Cambodian Ministry of Health and the World Health Organization (WHO) Office of the Western Pacific Region. The Australia New Zealand Clinical Trials Registry number is ACTRN12613000003774. 


\section{Participants and enrolment}

The inclusion criteria were all of: (1) male or nonpregnant female aged $>1$ year; (2) weight $\geq 10 \mathrm{~kg}$; (3) presentation with acute ( $\leq 10$ days), symptomatic (fever or history of fever), uncomplicated, $P$. vivax infection (mono- or mixed species infection); (4) $\geq 2$ vivax asexual parasites after reading 200 thick blood film fields; (5) written or verbal informed consent; (6) able and willing to participate; and (7) not currently taking any drugs or herbal remedies likely to cause haemolysis in G6PDd.

The exclusion criteria were any one of: (1) Hb concentration $<8 \mathrm{~g} / \mathrm{dL}$; (2) malaria danger sign/s (e.g. persistent vomiting, $\geq 2$ convulsions in previous 24 hours, prostration [23]), (3) clinically significant disease requiring treatment or further investigation; (4) on a QTc interval prolonging drug; (5) family history of cardiac related, sudden unexpected death; (6) pregnant, planning pregnancy or breast feeding; (7) for a G6PDd child $<5$ years - living >25 km from the research site; (8) allergic to or previous contraindicating adverse event to primaquine or dihydroartemisinin/piperaquine (DHAPP), and (9) taken an investigational drug within the previous 8 weeks.

\section{Conduct of clinical trial}

Patients presenting to the research team who gave consent were assessed for study entry with the following: (1) brief history and examination, (2) Giemsa-stained malarial thick and thin blood films, (3) Hb concentration (HemoCue AB, Ängelholm, Sweden), (4) G6PD status using the fluorescent spot test (FST) (G-6-PDH - Spot Test, Trinity Biotech, Plc, St. Louis, USA), and (5) a urine pregnancy test to detect beta human chorionic gonadotrophin (Biotest, Selangor, Malaysia).

Enrolled patients were admitted for the first 72 hours and had: (1) a detailed history and physical examination; (2) twice daily vital sign checks; (3) blood taken for (a) full blood and reticulocyte counts (RETc) (CellDyn 3200analyser, Abbott, Rungis, France), (b) G6PD enzyme quantification (Trinity Biotech Quantitative G6PD assay) adapted on the Integra 400 analyser (Roche Diagnostic, Meylan, France) [20], (c) G6PD genotyping by an inhouse polymerase chain reaction (PCR) [20], (d) $\mathrm{Hb}$ electrophoresis (MINICAP system, Sebia, Norcross, France) [20], (e) routine biochemistry-including haptoglobin and lactate dehydrogenase (LDH), and (f) plasma $\mathrm{Hb}$ (Plasma Hb Photometer, HemoCue AB, Ängelholm, Sweden); (4) blood films for malaria (D1-3, 7, 14-56), red cell morphology and manual RETc; (5) methaemoglobin estimation (Masimo oximeter, Irvine, CA, USA); and (6) urine colour graded $1-10$ by the research team using a colour chart [24] (urine colour was graded every time patients passed urine as inpatients and if they were able to produce a urine sample at the follow-up visits). Blood tests $\mathrm{a}, \mathrm{b}$ and e were performed on D0, 7, 28 and
56 and samples transported in a cool box to the Pasteur Institute in Phnom Penh for analysis. Vivax parasitaemia was quantified $(\mathrm{N} / \mu \mathrm{L})$ as the number of vivax parasites per 200 white cells on a thick blood film, assuming a total white cell count of $8,000 / \mu \mathrm{L}$. A thick blood film was declared negative after counting 200 thick fields. Discharged patients were followed up on D7, then weekly to D56. Health workers went in search of nonattendee patients.

\section{G6PD enzyme activity and G6PD status}

G6PD enzyme activity was classified as I to $\mathrm{V}$ according to the measured G6PD activity expressed as a percentage of population median [20]. G6PD status was determined by the results of the G6PD genotyping as wild type, G6PDd hemizygote male, G6PDd homozygous female or G6PDd heterozygous female. For all G6PDd patients, DNA was extracted from the buffy coat using the QIAamp DNA Blood Mini Kit (Qiagen, Courtaboeuf, France), according to the manufacturer's instructions. DNA was used to detect the most frequent mutations in the G6PD gene by a PCR/sequencing approach [20]: (1) in exon 6 for the Mahidol $(487 \mathrm{G}>\mathrm{A})$, Mediterranean $(563 \mathrm{C}>\mathrm{T})$ and Coimbra $(592 \mathrm{C}>\mathrm{T})$ variants; (2) in exon 9 for the Viangchan $(871 \mathrm{G}>\mathrm{A})$ and Chinese-5 (1024C $>\mathrm{T})$ variants; (3) in exon 11 for the Union $(1360 \mathrm{C}>\mathrm{T})$ variant; and (4) in exon 12 for the Canton (1376G>T) variant [20].

\section{Drug treatments and allocation}

We used DHAPP produced by Holley-Cotec, Beijing, under the brand name Duo-Cotecxin. Before being distributed in the health system, samples from new batches of DuoCotecxin were sent for analysis to an independent laboratory by the WHO Cambodia Office and found to be satisfactory. DHAPP was given once daily on D0, 1 and 2 by weight, as per the manufacturer's instructions and 2012 National Treatment Guidelines: one tablet for 10 to $<19 \mathrm{~kg}$, 1.5 tablets for 19 to $<30 \mathrm{~kg}$, two tablets for 30 to $<40 \mathrm{~kg}$, three tablets for 40 to $<79 \mathrm{~kg}$, and four tablets for $\geq 80 \mathrm{~kg}$. One DHAPP tablet contains $40 \mathrm{mg}$ of DHA and $320 \mathrm{mg}$ of PP. Primaquine (15 mg primaquine base/tablet) was given on D0 with the first dose of DHAPP and weekly thereafter for eight doses. The dosing regimen was designed by the research team (Table 1) and the target dose was $0.75 \mathrm{mg} / \mathrm{kg}$ of PQ base. Primaquine was first obtained from Cipla, India, and underwent satisfactory quality control at an external laboratory. Towards the end of the study, primaquine was obtained from the Government Pharmaceutical Organisation, Thailand, but not sent for external quality control.

If vomiting occurred within 30 minutes, a full dose of either or both drugs was re-administered; if between 31 and 60 minutes, half doses were given. All treatments were given supervised by study nurses. Other drugs were allowed as clinically indicated, e.g. paracetamol for fever. 
Table 1 Dose of weekly primaquine expressed as milligrams of primaquine base

\begin{tabular}{llll}
\hline Weight $(\mathrm{kg})$ & $\begin{array}{l}\text { Number of } \\
\text { primaquine tablets }\end{array}$ & $\begin{array}{l}\text { Primaquine } \\
\text { dose }(\mathrm{mg})\end{array}$ & $\begin{array}{l}\text { Primaquine dose } \\
(\mathrm{mg} / \mathrm{kg})\end{array}$ \\
\hline $10-17$ & 0.5 & 7.5 & $0.44-0.75$ \\
$18-25$ & 1 & 15 & $0.6-0.83$ \\
$26-35$ & 1.5 & 22.5 & $0.64-0.87$ \\
$36-45$ & 2 & 30 & $0.67-0.83$ \\
$46-55$ & 2.5 & 37.5 & $0.69-0.82$ \\
$56-75$ & 3 & 45 & $0.64-0.82$ \\
$\geq 76$ & 4 & 60 & $\leq 0.78$ \\
\hline
\end{tabular}

\section{Rescue treatment}

Patients who failed treatment (i.e. had a persistent or a recurrent vivax parasitaemia) were retreated with oral DHAPP. Those who developed falciparum malaria during follow-up were treated with atovaquone/proguanil, as per National Guidelines. Patients with persistent vomiting or severe malaria [24] received intravenous artesunate or, if unavailable, intramuscular artemether followed by oral treatment as above.

\section{Outcomes}

The primary outcome was patients completing all eight primaquine doses, i.e. not having primaquine stopped because of primaquine toxicity, defined by research team consensus as any one of: (1) a $>25 \%$ fall in baseline $\mathrm{Hb}$ by D7, (2) severe anaemia by D7 ( $\mathrm{Hb}<7 \mathrm{~g} / \mathrm{dL}$ for all ages), (3) haemoglobinuria (urine colour $\geq 8$, using a urine colour chart graded 1 to 10 [24]) for 2 days, (4) methaemoglobinaemia $>20 \%$, (5) a $>50 \%$ increase in creatinine from D0 with evidence of AHA, and (5) AHA necessitating a blood transfusion (added post hoc).

Secondary endpoints included: (1) changes over time of whole blood and plasma $\mathrm{Hb}$ concentrations and routine biochemical parameters, and (2) incidence of adverse events (AEs).

\section{Adverse events and safety monitoring}

AEs and serious AEs (SAEs) were defined and graded according to the 2004 US National Institutes of Health Division of AIDS toxicity table [25]. All SAEs were to be reported within 24 hours to the study principal investigator and ethics committees. An independent Drug Safety and Monitoring Board (DSMB) monitored study safety; data from G6PDd patients was sent to the DSMB as they became available.

\section{Sample size}

Sample size was based on demonstrating a difference in primaquine-related toxicity between the two G6PD groups. Such data are lacking in vivax-infected patients, so, assuming similar $\mathrm{Hb}$ dynamics between $P$. vivax and $P$. falciparum [26], we used a falciparum database of South-East Asian patients treated with artemisinin-based combinations; 374/6,882 (5.4\%) had a fall in baseline haematocrit $\geq 25 \%$ by D7. We hypothesised primaquine toxicity rates of $5 \%$ (G6PDn) and $25 \%$ (G6PDd). Using a power of 0.8 , a two-sided alpha of 0.05 , and a $2: 1$ allocation in favour of the G6PDd arm, the sample size was 92 and 46 patients, rounded up to 100 G6PDd and 50 G6PDn patients. Between $\sim 580$ and $\sim 1,200$ patients would need to be screened to recruit 100 G6PDd patients, based on reported G6PDd prevalence rates [19].

\section{Data management and statistical methods}

Data were entered onto standardised case record forms, checked against source documents, double entered into Epidata, and analysed using Stata v13 (Stata Corporation, College Station,mTX, USA). Proportional data were compared using chi-squared or Fisher's exact tests, as appropriate, and continuous data by student's $t$ (normally distributed data) or Mann-Whitney U (skewed data) tests. The relationship between the fractional fall in $\mathrm{Hb}$ on $\mathrm{D} 7$ versus baseline and the $\mathrm{mg} / \mathrm{kg}$ dose of primaquine was assessed by Spearman rho test (skewed data), and with the baseline G6PD enzyme activity by Pearson's correlation coefficient (transforming the G6PD data to become normally distributed).

\section{Results}

\section{Patient disposition and baseline characteristics}

From January 2013 to January 2014, 361 patients were screened and 75 with mono vivax infections were enrolled into the study; eight did not complete follow-up (Fig. 1). Because the sample size requirement for G6PDn was met in Pailin, we only recruited patients at the other two sites if the FST result showed they were G6PDd. Most patients were male $(n=63)$ of median age 24 years [range 5-63, interquartile range (IQR) 9-46]. Median female age was 29 years (range 9-56, IQR 15-45). Fifteen patients $(20 \%)$ were $<18$ years of age (Table 2 ). A total of 18 patients were G6PDd: 17 had the Viangchan variant (14 hemizygous males, 3 heterozygous females), and one male had the Canton variant.

Baseline demographic, clinical and laboratory characteristics were similar between the two G6PD groups (Table 2), except for reported rates of abdominal pain, abnormal urine colour, mean body temperature and G6PD activity. Four PCR-determined G6PD wild-type patients had low G6PD enzyme activities that were probably due to delayed measurement; in three patients, the baseline values were inconsistent with later G6PD activity values and in one there were no other G6PD activity values. All such values have been excluded from Table 2. Two G6PDd patients had missing baseline 


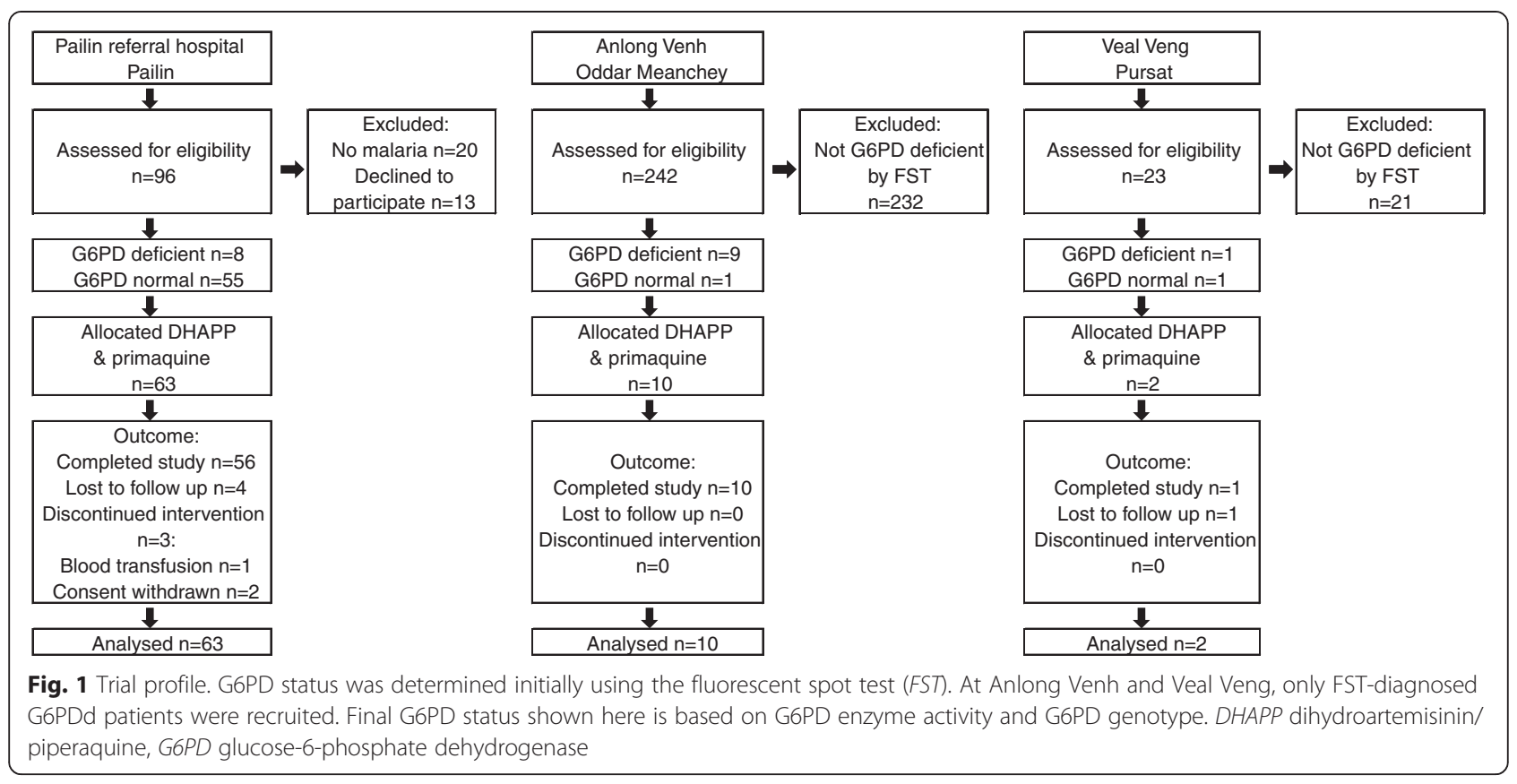

enzyme activity values (also excluded from Table 2) but were classified using post D0 G6PD enzyme activity results. Of the 18 G6PDd patients, 13 were class II ( 1 to $<10 \%$ population median of $12 \mathrm{U} / \mathrm{g} \mathrm{Hb}$ ) and five were class III ( $\geq 10$ to $60 \%$ ) G6PDd. Three patients had discordant FST results: two from Anlong Venh and Veal Veng were diagnosed as FST G6PDd but were subsequently confirmed as G6PD wild type and one FST-diagnosed G6PD normal patient was later confirmed PCR G6PDd (Fig. 2).

\section{Primary outcome}

One 23-year-old G6PDd male, diagnosed subsequently with G6PDd Viangchan, had a SAE-clinically significant anaemia that was probably primaquine related and was treated by blood transfusion. His D0 $\mathrm{Hb}$ fell from 10.0 to $7.5 \mathrm{~g} / \mathrm{dL}$ on D3 and to $7.2 \mathrm{~g} / \mathrm{dL}$ on D5, for a fractional fall of $28 \%$. He developed slowly progressive dyspnoea and by D5 he was breathless walking the short distance from his bed to the toilet. He did not have gross haemoglobinuria-his darkest urine colour was graded 4 . He was not given further primaquine. When questioned later, he said he went to a village shop for stomach ache and fever and was advised by the drug seller to take cimetidine and ciprofloxacin; he took two doses of both cimetidine $400 \mathrm{mg}$ and ciprofloxacin $500 \mathrm{mg}$ one day before enrolment but had not reported this to the study team at enrolment.

On D3, 4/18 (22.2 \%) G6PDd versus 0/57 G6PDn had a $>25 \%$ fall in $\mathrm{Hb}(P=0.003)$; all four patients were G6PDd Viangchan: three hemizygous males and one heterozygous female. Their D0-D3 Hb concentrations were: $16.0-11.3,14.8-9.0,12.8-9.1$ and $13.2-9.8 \mathrm{~g} / \mathrm{dL}$. Compared to the G6PDn group, the median (range) fractional fall in haematocrit was significantly higher $(P=$ $0.0001)$ in the G6PDd group: $-15.26 \%$ (-39.1 to 3.6) versus $-6.15 \%$ ( -19.1 to 22.8$)$.

On D7, two of the males with $>25 \%$ fall in $\mathrm{Hb}$ on D3 had persistent fractional falls in haemoglobin $>25 \%$ : 14.8-9.9 and 12.8-8.9 g/dL. Compared to the G6PDn group, the median fractional fall in $\mathrm{Hb}$ was significantly higher $(P=0.0002)$ in the G6PDd group: $-16.3 \%(-33.1$ to 6.5$)$ versus $-3.7 \%$ ( -17.5 to 24.3$)$. Primaquine was not stopped in these two male patients because they were well.

By D7, the cumulative number of patients with protocoldefined primaquine toxicity (i.e. including those identified on D3 and the transfused male) was 5/18 G6PDd (27.7 \%) versus $0 / 57$ from the G6PDn group $(P=0.00049)$. This difference between the two arms was still significant if the two D3 patients with transient PQ toxicity were excluded: $3 / 18$ $(16.6 \%)$ versus $0 \%(P=0.01)$. No patients developed severe anaemia, haemoglobinuria, methaemoglobin $>4.9 \%$ or AHA-related acute kidney injury.

\section{Secondary outcomes}

The median nadir $\mathrm{Hb}$ concentration occurred on D2 in both groups and began to rise on D3 in the G6PDn group and D14 in the G6PDd group (Fig. 3, Table 3). The days of the greatest decline in the absolute median $\mathrm{Hb}$ concentration and fractional median change in $\mathrm{Hb}$ concentrations were D2 and D7, respectively (Fig. 3, Additional file 1). The differences in these two parameters by G6PD status were statistically significant for the 
Table 2 Baseline characteristics in the two glucose-6-phosphate dehydrogenase groups

\begin{tabular}{|c|c|c|c|}
\hline \multirow[t]{2}{*}{ Parameter } & \multirow{2}{*}{$\begin{array}{l}\text { G6PD deficient } \\
n=18\end{array}$} & \multirow{2}{*}{$\begin{array}{l}\text { G6PD normal } \\
\mathrm{n}=57\end{array}$} & \multirow[t]{2}{*}{$P$ value } \\
\hline & & & \\
\hline Age (years) & $25(5-56)$ & $24(7-63)$ & 0.95 \\
\hline Aged $<18$ years & $5(27.8)$ & $10(17.5)$ & 0.34 \\
\hline Male, female & $15(83.3), 3$ & $48(84.2), 9$ & 0.93 \\
\hline Weight (kg) & $54(20-56)$ & $53(14-88)$ & 0.83 \\
\hline \multicolumn{4}{|l|}{ Symptoms } \\
\hline Headache & $14(77.8)$ & $53(92.9)$ & 0.07 \\
\hline Fever & $14(77.8)$ & $48(84.2)$ & 0.53 \\
\hline Chills & $12(66.7)$ & $47(82.5)$ & 0.15 \\
\hline Abdominal pain & $4(22.2)$ & $28(49.1)$ & 0.04 \\
\hline Nausea & $3(16.7)$ & $14(24.6)$ & 0.48 \\
\hline Cough & $1(5.6)$ & $7(12.3)$ & 0.42 \\
\hline Abnormal urine colour & $9(50)$ & $7(12.3)$ & 0.001 \\
\hline \multicolumn{4}{|l|}{ Signs } \\
\hline $\begin{array}{l}\text { Mean (SD) } \\
\text { temperature }\left({ }^{\circ} \mathrm{C}\right)\end{array}$ & $37.8(0.9)$ & $38.6(1.0)$ & 0.002 \\
\hline Mean (SD) pulse (mmHg) & 92 (18.6) & $96(11.1)$ & 0.32 \\
\hline $\begin{array}{l}\text { Mean (SD) systolic } \\
\text { BP }(\mathrm{mmHg})\end{array}$ & $105(15.5)$ & $110(12.4)$ & 0.17 \\
\hline $\begin{array}{l}\text { Mean (SD) diastolic } \\
\text { BP }(\mathrm{mmHg})\end{array}$ & $61(11)$ & $66(10)$ & 0.09 \\
\hline $\begin{array}{l}\text { Normal conjunctival } \\
\text { colour }\end{array}$ & $18(100)$ & $56(98.3)$ & 0.57 \\
\hline Pale palms & $1(5.6)$ & $5(8.8)$ & 0.66 \\
\hline Palpable liver & $1(5.6)$ & $2(3.5)$ & 0.69 \\
\hline Palpable spleen & $1(5.6)$ & $2(3.5)$ & 0.69 \\
\hline \multicolumn{4}{|l|}{ Haematological parameters } \\
\hline $\begin{array}{l}\text { G6PD activity } \\
(\mathrm{U} / \mathrm{g} \mathrm{Hb})\end{array}$ & $0.85(0.1-1.5)^{\mathrm{a}}$ & $12(6.9-18.5)$ & 0.000 \\
\hline Normal haemoglobin & $11(61.1)$ & $31(54.4)$ & \\
\hline Heterozygous HbE & $5(27.8)$ & $20(35.1)$ & \\
\hline Homozygous HbE & 0 & $1(1.75)$ & \\
\hline $\begin{array}{l}\text { Alpha/beta } \\
\text { thalassaemia }\end{array}$ & $1(5.6)$ & $5(8.7)$ & 0.4 \\
\hline Haemoglobin (g/dL) & $13.0(9.6-16)$ & $13.5(9-16.3)$ & 0.46 \\
\hline $\begin{array}{l}\text { Total white cell } \\
\text { count } \times 10^{3} / \mu \mathrm{L}\end{array}$ & $5.15(1.4-8.3)$ & $5.0(1.1-11.5)$ & 0.61 \\
\hline Platelet count $\times 10^{3} / \mu \mathrm{L}$ & $126(42-187)$ & $99(12-204)$ & 0.26 \\
\hline Vivax parasitaemia/ $\mu \mathrm{L}$ & 6,420 (159-9326) & $7,888(220-59,542)$ & 0.13 \\
\hline
\end{tabular}

Unless otherwise stated, continuous data are shown as median (range) Proportional data are shown as N (\%)

$B P$ blood pressure, G6PD glucose-6-phosphate dehydrogenase $H b E$ haemoglobin E, SD standard deviation

${ }^{\text {a }}$ substituting the two missing enzyme values with post Do values: 0.9 (0.1-2.6) $\mathrm{U} / \mathrm{g} \mathrm{Hb}$

first 14 days of follow-up (Table 3). The largest median (range) $\mathrm{Hb}$ difference $(P=0.0002)$ was on D7: $-2.2 \mathrm{~g} / \mathrm{dL}$ $(-4.9$ to $0.8, \mathrm{G} 6 \mathrm{PDd})$ versus $-0.5 \mathrm{~g} / \mathrm{dL}(-2.2$ to 2.8 ,
G6PDn), $\Delta=-1.7 \mathrm{~g} / \mathrm{dL}(-2.7$ to 2.0$)$. The fractional fall in $\mathrm{Hb}$ on $\mathrm{D} 7$ versus baseline was unrelated to the $\mathrm{mg} / \mathrm{kg}$ dose of administered primaquine in the G6PDn $(P=$ $0.68)$ or the G6PDd group $(P=0.77)$ but was associated weakly with baseline G6PD enzyme activity $(P=0.013)$, for a coefficient of variation of $\sim 8 \%$. Hb recovery to the median D0 $\mathrm{Hb}$ occurred on D28 (G6PDn) and D35 (G6PDd, Fig. 2); the median recovery time for individual patients was 28 days for both arms $(P=0.48)$. Out of the 63 patients, 14 (22.2\%) had lower median Hb concentrations on D56 versus D0, which was unrelated to G6PD status $(P=1.0)$.

G6PDd patients had higher median LDH concentrations and proportions with values above the upper limit of normal, higher median RETc on D7, and lower median haptoglobin concentrations on D7-D56 (Table 4). Plasma $\mathrm{Hb}$, serum unconjugated bilirubin and creatinine concentrations were similar between both groups. All patients cleared their vivax parasites by D2 and none had recurrent malaria during follow-up.

\section{Harms and adverse events}

Patients tolerated their treatments well. Nineteen patients had a total of 38 clinical AEs; 19 (50\%) of these AEs occurred on D0-2 (Table 5). Most were mild and considered unrelated or unlikely to be primaquine related. One G6PDn patient had early vomiting on D0 and was re-dosed without further incident.

\section{Discussion}

This is the first study to evaluate the tolerability of a weekly anti-relapse primaquine regimen in patients with acute vivax malaria and South-East Asian variants of G6PDd. Within the first week, approximately one quarter of G6PDd patients experienced substantial drops ( $>25 \%)$ in their $\mathrm{Hb}$ concentrations, including one patient whose progressive fall in $\mathrm{Hb}$ necessitated a blood transfusion. These results preclude the use of unsupervised weekly primaquine in settings where severe G6PDd is present, and mandate prior testing for G6PDd.

The male patient who required a blood transfusion had not mentioned his visit to the village shop where he was advised to take cimetidine and ciprofloxacin. Cimetidine is a known cytochrome P450 3A4 inhibitor [27] and ciprofloxacin has been implicated in one case report of AHA in a G6PDd patient [28]. Thus, a drugdrug interaction and/or direct red cell toxicity may have contributed to his worsening anaemia. This is a reminder for clinicians to be vigilant when prescribing primaquine to patients already taking drugs that could enhance the haemolytic potential of primaquine.

Our study focused on the most vulnerable group of patients at risk of AHA. The criteria of primaquine toxicity were selected to detect events that could potentially 


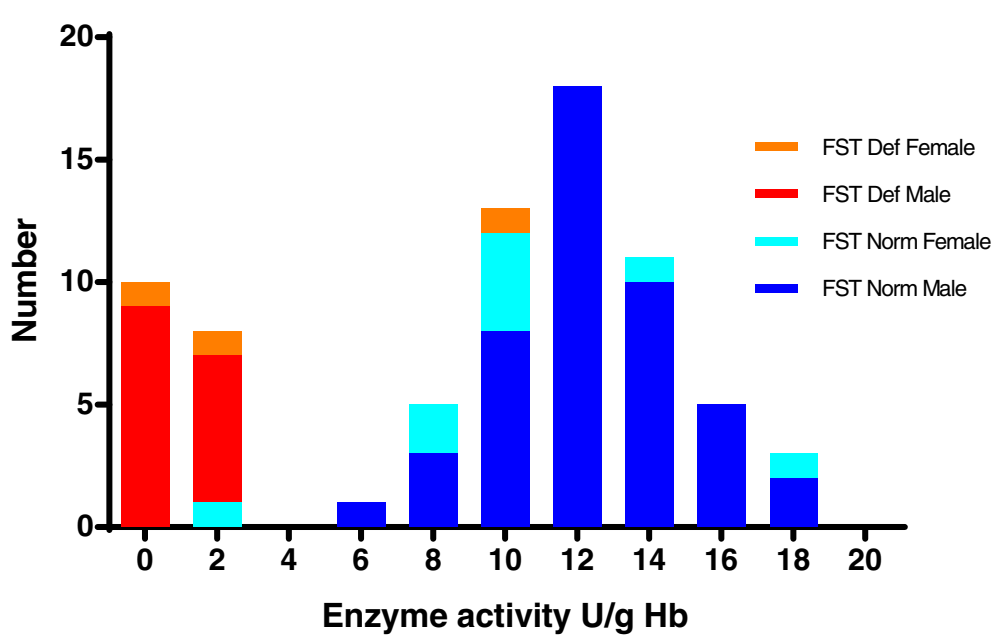

Fig. 2 Results of the fluorescent spot test as a function of the measured G6PD enzyme activity. One G6PD enzyme value was unavailable for a fluorescent spot test (FST)-diagnosed G6PD deficient male who was confirmed G6PD wild type by polymerase chain reaction

be dangerous to unsupervised patients who make up the vast majority in malaria-endemic countries. All of our G6PDd hemizygous males and the three heterozygous females experienced a fall in $\mathrm{Hb}$ during follow-up, especially within the first week. However, aside from the transfused G6PDd male, none had significant symptoms of anaemia and all had later increases in their $\mathrm{Hb}$ concentrations despite continued dosing. Indeed, primaquine was continued in the two G6PDd males with fractional $\mathrm{Hb}$ falls $>25 \%$ on $\mathrm{D} 7$ because they were clinically well and had adequate $\mathrm{Hb}$ concentrations of $\sim 9 \mathrm{~g} / \mathrm{dL}$. As expected, the G6PDn patients tended to have smaller declines in $\mathrm{Hb}$ concentrations and they tolerated weekly primaquine despite some of them experiencing drops in $\mathrm{Hb}$ exceeding $2 \mathrm{~g} / \mathrm{dL}$.

The key to the safe use of primaquine and, in the future, tafenoquine as anti-relapse treatment to achieve $P$. vivax radical cure is the accurate diagnosis of G6PDd and identifying those with more severe G6PDd. Indeed, tafenoquine registration trials are excluding patients with enzyme activities $<70 \%$ of the population median (NCT02216123) [29]. In our setting, a patient with severe G6PDd who could be misclassified as G6PDn and would thus receive the appropriate primaquine antirelapse dose of $0.5 \mathrm{mg} / \mathrm{kg} / \mathrm{d}$ (30 $\mathrm{mg}$ in an adult) would probably develop severe AHA [12, 17, 22, 30]. G6PDd testing is currently laboratory-based in Cambodia but the wider availability of a promising and robust pointof-care rapid diagnostic test (RDT) [31] capable of detecting patients with G6PD enzyme activities <30\% $(<3.6 \mathrm{U} / \mathrm{gHb})$ of the Cambodian median (i.e. those at the lower end of the G6PD activity spectrum) would open up the option of G6PDd testing by village malaria workers (VMWs), referring RDT-diagnosed G6PDd patients for medical supervision and treating the other patients in the community. Such a strategy should be piloted to assess its feasibility, VMW acceptability, cost, efficacy and safety.

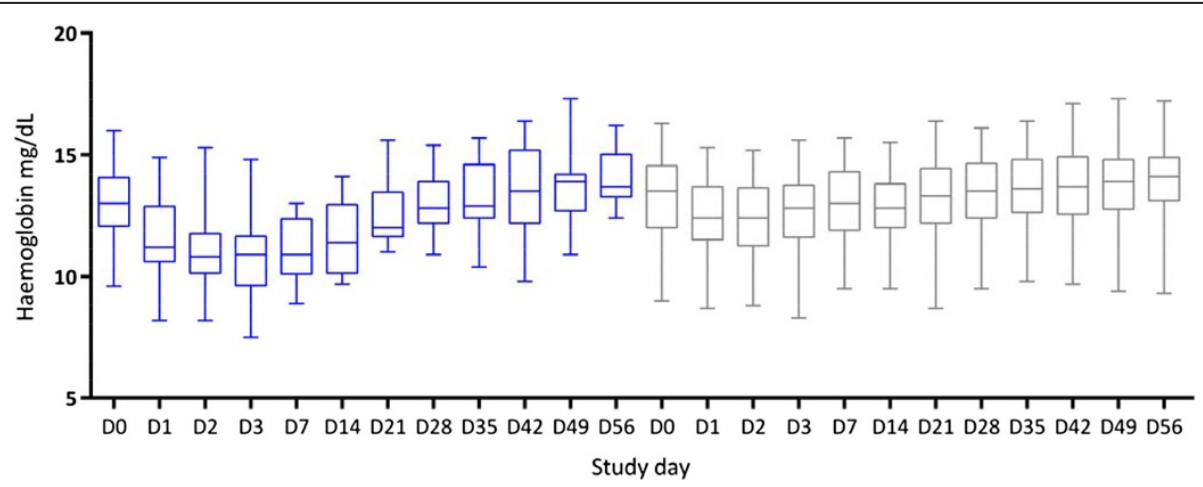

Fig. 3 Boxplots (median, interquartile range, full range) of HemoCue-measured haemoglobin (Hb) concentrations over time as a function of G6PD status. Post transfusion $\mathrm{Hb}$ concentrations have been excluded. Blue box plots are G6PD-deficient patients. G6PD glucose-6-phosphate dehydrogenase 
Table 3 Changes in haemoglobin concentrations in during the first 28 days of follow-up

\begin{tabular}{|c|c|c|c|c|c|c|c|c|c|}
\hline \multirow[t]{2}{*}{ Day } & G6PD deficient & G6PD normal & \multirow[t]{2}{*}{$P$} & G6PD deficient & G6PD normal & \multirow[t]{2}{*}{$P$} & G6PD deficient & G6PD normal & \multirow[t]{2}{*}{$P$} \\
\hline & \multicolumn{2}{|c|}{ Haemoglobin concentration $(\mathrm{g} / \mathrm{dL})$} & & \multicolumn{2}{|c|}{$\begin{array}{l}\text { Changes in haemoglobin } \\
\text { concentrations versus day } 0\end{array}$} & & \multicolumn{2}{|c|}{$\begin{array}{l}\text { Fractional changes in haemoglobin } \\
\text { concentrations versus day } 0\end{array}$} & \\
\hline U & $13.0(9.6 t$ & 13.5 (9 to 16.3 ) & 0.46 & - & - & & - & - & \\
\hline & $11.2(8.2$ to 14.9$)$ & $12.4(8.7$ to 15.3$)$ & 0.041 & $-1.5(-4.0$ to 1.1$)$ & $-0.8(-3.2$ to 3.3$)$ & 0.059 & $-12.5(-27.1$ to 8.7$)$ & $-6.5(-22.7$ to 28.7$)$ & 0.028 \\
\hline & $10.8(8.2$ to 15.3$)$ & 12.4 (8.8 to 15.2$)$ & 0.006 & $-1.7(-5.0$ to 0.6$)$ & -1 ( -3.5 to 2.1$)$ & 0.047 & $-13.3(-31.2$ to 4.1$)$ & $-7.4(-23.6$ to 25.2$)$ & 0.029 \\
\hline & 10.9 (7.5 to 14.8$)$ & $12.8(8.3$ to 15.6$)$ & 0.0002 & $-1.9(-5.8$ to 0.4$)$ & $-0.8(-2.6$ to 2.9$)$ & 0.0003 & $-15.3(-39.2$ to 3.6$)$ & $-6.1(-19.1$ to 22.8$)$ & 0.000 \\
\hline 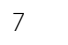 & 10.9 (8.9 to 13$)$ & 13 (9.5 to 15.7$)$ & 0.0001 & -2.2 (-4.9 to 0.8$)$ & $-0.5(-2.2$ to 2.8$)$ & 0.0002 & $-16.3(-33.1$ to 6.5$)$ & $-3.7(-17.5$ to 23.3$)$ & 0.000 \\
\hline 14 & $11.4(9.7$ to 14.1$)$ & 12.8 (9.5 to 15.5$)$ & 0.0067 & -1.7 (-3.0 to 0.3$)$ & $-0.5(-4.2$ to 2.1$)$ & 0.005 & $-12.9(-22.7$ to 2.7$)$ & $-4(-25.7$ to 18.1$)$ & 0.00 \\
\hline 21 & $12(11$ to 15.6$)$ & 13.3 (8.7 to 16.4 ) & 0.039 & -0.6 (-2 to 1.6$)$ & 0.3 (- 3.5 to 2.1$)$ & 0.1 & $-4.7(-15.1$ to 14.6$)$ & $2.1(-24.3$ to 16.8$)$ & 0.11 \\
\hline 28 & 12.8 (10.9 to 15.4$)$ & $13.5(9.5$ to 16.1$)$ & 0.26 & 0.2 (-2 to 2.6$)$ & 0.3 (-2.3 to 2.7 ) & 0.62 & $1.5(-13.6$ to 27.1$)$ & $2.3(-15.8$ to 21.2$)$ & 0.58 \\
\hline
\end{tabular}

All data are shown as median (range)

G6PD glucose-6-phosphate dehydrogenase

In 2012, the WHO recommended the use of single low-dose primaquine $(0.25 \mathrm{mg} / \mathrm{kg})$ without testing for G6PDd to block the transmission of artemisininresistant $P$. falciparum [32]. Limited evidence at that time suggested this dose would be tolerated in all G6PDd patients. Our findings support this notion and suggest that $0.25 \mathrm{mg} / \mathrm{kg}$ would be tolerated well in falciparum-infected Cambodians with severe G6PDd without the need for testing for G6PDd. This should help inform a decision to deploy low-dose primaquine, especially in Cambodia, the epicentre of artemisininresistant $P$. falciparum $[15,33]$.
This study had limitations. The total number of G6PDd patients was only 18 , most were hemizygous males, and most had the Viangchan variant; their measured enzyme activities were low (median $<1 \mathrm{U} / \mathrm{g} \mathrm{Hb}$ ), placing them at the severe end of the G6PD spectrum. Perhaps surprisingly, this study is currently the largest clinical series of primaquine-treated, vivax-infected patients with mostly severe G6PDd. Our findings are consistent with other smaller primaquine challenge studies $(0.75 \mathrm{mg} / \mathrm{kg})$ in otherwise healthy volunteers with Mediterranean G6PDd and patients who had $\mathrm{Hb}$ falls of approximately $20-25 \%$ [12, 34-37]. More safety data are needed from larger safety studies in

Table 4 Changes in laboratory parameters over time

\begin{tabular}{|c|c|c|c|c|c|c|c|c|c|c|c|c|}
\hline \multirow[t]{2}{*}{ Parameter } & G6PDd & G6PDn & $P$ & G6PDd & G6PDn & $P$ & G6PDd & G6PDn & $P$ & G6PDd & G6PDn & $P$ \\
\hline & \multicolumn{3}{|l|}{ D0 } & \multicolumn{3}{|l|}{ D7 } & \multicolumn{3}{|l|}{ D28 } & \multicolumn{3}{|l|}{ D56 } \\
\hline \multirow[t]{2}{*}{ Reticulocyte count (\%) } & 1.7 & 1.3 & 0.051 & 3 & 1.9 & 0.0009 & 1.4 & 1.5 & 0.056 & 1 & 1.2 & 0.98 \\
\hline & $(0.6-3.8)$ & $(0.5-4.5)$ & & $(1.6-3)$ & $(0.6-7)$ & & $(0.9-4.8)$ & $(0.3-6)$ & & $(0.5-2.4)$ & $(0.4-2.6)$ & \\
\hline \multirow{2}{*}{$\begin{array}{l}\text { Plasma haemoglobin } \\
\text { (g/dL) }\end{array}$} & 0.1 & 0.085 & 0.3 & 0.05 & 0.05 & 0.81 & 0.03 & 0.04 & 0.75 & 0.08 & 0.08 & 0.9 \\
\hline & $(0.01-13.5)$ & $(0.01-0.71)$ & & $(0.02-0.46)$ & $(0-0.27)$ & & $(0.01-0.13)$ & $(0-0.28)$ & & $(0.04-0.09)$ & $(0-0.24)$ & \\
\hline \multirow[t]{2}{*}{ Haptoglobin (g/L) } & 0.34 & 0.59 & 0.21 & 0.35 & 0.72 & 0.006 & 0.69 & 0.98 & 0.03 & 0.54 & 0.87 & 0.029 \\
\hline & $(0-1.48)$ & $(0-2.16)$ & & $(0.09-1.07)$ & $(0.1-1.83)$ & & $(0.16-1.19)$ & $(0.04-2.32)$ & & $(0.08-1.25)$ & $(0.06-2.22)$ & \\
\hline \multirow[t]{2}{*}{ Low haptoglobin ${ }^{a}$} & $8 / 16$ & $14 / 56$ & 0.056 & $5 / 14$ & $8 / 57$ & 0.11 & $2 / 14$ & $3 / 52$ & 0.28 & $5 / 14$ & $4 / 49$ & 0.02 \\
\hline & $(50)$ & (25) & & $(35.7)$ & $(14.1)$ & & $(14.3)$ & $(5.8)$ & & $(35.7)$ & $(8.2)$ & \\
\hline \multirow[t]{2}{*}{ LDH (IU/L) } & 308 & 231 & 0.01 & 350 & 196 & 0.0002 & 319.5 & 183.5 & 0.005 & 296.5 & 181 & 0.008 \\
\hline & $(127-800)$ & $(23-611)$ & & $(178-700)$ & $(58-783)$ & & $(121-619)$ & $(37-593)$ & & $(154-746)$ & $(118-522)$ & \\
\hline \multirow[t]{2}{*}{ High $\mathrm{LDH}^{\mathrm{a}}$} & $13 / 17$ & $18 / 56$ & 0.002 & $12 / 15$ & $12 / 57$ & 0.000 & $10 / 14$ & $7 / 52$ & 0.001 & $8 / 14$ & $7 / 49$ & 0.002 \\
\hline & $(76.5)$ & $(32.1)$ & & (80) & $(21.1)$ & & (71.4) & $(13.5)$ & & $(57.1)$ & $(14.3)$ & \\
\hline \multirow{2}{*}{$\begin{array}{l}\text { Unconjugated } \\
\text { bilirubin (mg/L) }\end{array}$} & 2.5 & 3.75 & 0.63 & 1.7 & 1.7 & 0.9 & 1.4 & 1.4 & 0.66 & 1.45 & 1.5 & 0.59 \\
\hline & $(0.6-9.8)$ & $(0.5-14.3)$ & & $(0.4-4.8)$ & $(0.19-3.1)$ & & $(0.7-3.6)$ & $(0.2-4.3)$ & & $(0.6-3.4)$ & $(0.5-4.3)$ & \\
\hline \multirow[t]{2}{*}{ Creatinine $(\mu \mathrm{mol} / \mathrm{L})$} & 58 & 74 & 0.003 & 58 & 63 & 0.13 & 54.5 & 60.5 & 0.29 & 54.5 & 58 & 0.32 \\
\hline & (28-86) & $(35-90)$ & & $(28-83)$ & $(28-85)$ & & $(19-82)$ & $(27-99)$ & & $(24-80)$ & $(26-84)$ & \\
\hline
\end{tabular}

a numerator/denominator (\%)

Low below the lower limit of normal for haptoglobin LLN $(0.3 \mathrm{~g} / \mathrm{L})$, High above the upper limit of normal for LDH (255 IU/L)

G6PDd glucose-6-phosphate dehydrogenase deficient, G6PDn glucose-6-phosphate dehydrogenase normal, $L D H$ lactate dehydrogenase 
Table 5 Summary of reported or detected clinical adverse events and their relationships to study drugs

\begin{tabular}{|c|c|c|c|c|c|c|}
\hline \multirow[t]{3}{*}{ Adverse event } & \multirow{2}{*}{\multicolumn{3}{|c|}{$\begin{array}{l}\begin{array}{l}\text { Unrelated or } \\
\text { unlikely related }\end{array} \\
\text { Severity }\end{array}$}} & \multirow{2}{*}{\multicolumn{3}{|c|}{$\begin{array}{l}\text { Possibly or } \\
\text { probably related } \\
\text { Severity }\end{array}$}} \\
\hline & & & & & & \\
\hline & Mild & Moderate & Severe & Mild & Moderate & Severe \\
\hline Abdominal pain & 4 & 1 & & & & \\
\hline Epigastric pain & & 2 & & 1 & & \\
\hline Anorexia & & & & 1 & & \\
\hline Nausea & 1 & & & 1 & & \\
\hline Vomiting & & & & 1 & 1 & \\
\hline Diarrhoea & 2 & & & & & \\
\hline Jaundice & & & & 1 & & \\
\hline Pale conjunctivae & & & & & 2 & \\
\hline Anaemia & & & & & & 1 \\
\hline Back pain & & 1 & & & & \\
\hline $\begin{array}{l}\text { Change in urine } \\
\text { colour }\end{array}$ & & & & & 1 & \\
\hline Headache & 4 & 1 & & & & \\
\hline Dizziness & & & & 2 & & \\
\hline Hearing loss & 1 & & & 1 & & \\
\hline Asthenia & 2 & & & 1 & 2 & \\
\hline Sore throat & 1 & & & & & \\
\hline Fever & & 1 & & & & \\
\hline Chills & & 1 & & & & \\
\hline
\end{tabular}

patients with different G6PDd variants and in heterozygous G6PDd females who represent a therapeutic challenge. The small number of G6PDd patients recruited meant that the original G6PDd sample size (100) was far from achieved. Limited data suggest that Mediterranean variant G6PDd protects against clinical $P$. vivax disease $[38,39]$ so researchers need to take this possibility into account when planning studies. Despite the loss of power, key analyses still yielded significant comparisons. Adult males made up the majority of recruited patients, in keeping with the malaria epidemiology in Cambodia, and patients with a baseline $\mathrm{Hb}$ of $<8 \mathrm{~g} / \mathrm{dL}$ were excluded. Therefore, the findings of this study must be applied with caution to children and cannot be extrapolated to those with lesser degrees of G6PDd or to adults and children with moderately severe anaemia of $<8$ $\mathrm{g} / \mathrm{dL}$. The latter is an urgent group for further research.

\section{Conclusions}

This is the first study to evaluate weekly primaquine in vivax-infected patients with low or very low G6PD enzyme activities. In our setting, primaquine should not be given as anti-relapse treatment without knowing the G6PD status of patients and should be given under medical supervision to those found to be G6PDd. Other National Malaria Control Programmes should assess weekly primaquine in G6PDd patients to inform their elimination strategies.

\section{Additional file}

\section{Additional file 1: Fractional changes in haemoglobin}

concentrations on given follow-up days versus baseline over time as a function of G6PD status. Post transfusion haemoglobin concentrations have been excluded. Blue box plots (left) are glucose-6phosphate deficient patients. D10 $=\mathrm{Hb}$ on D1 $-\mathrm{Hb}$ on D0 $\times 100 \% / \mathrm{Hb}$ on D0. (DOCX $345 \mathrm{~kb})$

\section{Abbreviations}

AE: adverse event; AHA: acute haemolytic anaemia; AIDS: acquired immune deficiency syndrome; D: day; DHAPP: dihydroartemisinin/piperaquine; DSMB: Drug Safety \& Monitoring Board; FST: fluorescent spot test; G6PD: glucose-6-phosphate dehydrogenase; G6PDd: glucose-6-phosphate dehydrogenase deficiency/deficient; G6PDn: glucose-6-phosphate dehydrogenase normal; $\mathrm{Hb}$ : haemoglobin; LDH: lactate dehydrogenase; PCR: polymerase chain reaction; RDT: rapid diagnostic test; RETc: reticulocyte count; SAE: serious adverse event; VMW: village malaria workers.

\section{Competing interests}

The authors declare that they have no competing interests.

\section{Authors' contributions}

SKheng (study principal investigator), SM, WRJT, SB, DM, JKB, NT and EC developed the protocol. SKheng, SM, WRIT, NT, KK, PS, SKim, CV, PL, JKB and SB participated in prestudy training and study execution. CMC contributed intellectually to the study. VK, SKim and KK managed the data and assisted WRT in data analysis. AK and PT carried out and interpreted the clinical laboratory analyses. DM carried out the molecular laboratory analyses. WRJT, JKB, SB, SKheng and DM wrote the first draft of the paper. PR critically reviewed the protocol and the manuscript. All co-authors have read and approved the final manuscript.

\section{Acknowledgements}

We wish to express our sincere and profound thanks to the patients who took part in this study and to the nurses and laboratory staff who contributed to its successful and safe execution. We thank our DSMB who reviewed the G6PDd data in real time and provided very valuable and timely responses and advice: Drs Toby Leslie (Chairperson), Chanthap Lon, Isabella Ribeiro and Professor Lucio Luzzatto. Funding for this study was obtained by PR of WHO Geneva via a grant from UKAid without which this study would not have taken place. We record our profound gratitude to the taxpayers of the United Kingdom. WRJT was part supported by France Expertise International through the $5 \%$ initiative as a consultant to CNM in operational research and he expresses "ses remerciements profonds au peuple français." JKB is supported by Wellcome Trust grant B9RIIXO. DM is supported the French Ministry of Foreign Affairs and SKim was part funded by a grant from the Asia Pacific Malaria Elimination Network. None of the funders had any role in study design, data collection, analysis, and interpretation, or writing of the manuscript or in the decision to submit the manuscript for publication. The views expressed in the article are those of the authors and are not to be regarded as official views of the WHO.

\section{Author details}

${ }^{1}$ National Center for Parasitology, Entomology and Malaria Control, Phnom Penh, Cambodia. ${ }^{2}$ Service de Médecine Tropicale et Humanitaire, Hôpitaux Universitaires de Genève, Geneva, Switzerland. ${ }^{3}$ Mahidol Oxford Tropical Medicine Research Unit, 420/60 Rajvithi Road, Bangkok 10400, Thailand. ${ }^{4}$ WHO Cambodia Country Office, Pasteur Street, Phnom Penh, Cambodia. ${ }^{5}$ Pailin Referral Hospital, Pailin, Cambodia. ${ }^{6}$ Anlong Veng Referral Hospital, Anlong Venh, Oddar Meanchey, Cambodia. ${ }^{7}$ Institut Pasteur in Cambodia, Phnom Penh, Cambodia. ${ }^{8}$ Pramoy Health Centre, Veal Veng, Pursat, Cambodia. ${ }^{9} \mathrm{WHO}$ Headquarters, Geneva, Switzerland. ${ }^{10}$ Eijkman Oxford Clinical Research Unit, Jakarta, Indonesia. ${ }^{11}$ Centre for Tropical Medicine, Nuffield Department of Medicine, University of Oxford, Oxford, UK. ${ }^{2}$ WHO Western Pacific Regional Office, Manila, Philippines. 
Received: 9 March 2015 Accepted: 29 July 2015

Published online: 25 August 2015

\section{References}

1. Tjitra E, Anstey NM, Sugiarto P, Warikar N, Kenangalem E, Karyana M, et al. Multidrug-resistant Plasmodium vivax associated with severe and fatal malaria: a prospective study in Papua, Indonesia. PLoS Med. 2008;5, e128.

2. Genton B, D'Acremont V, Rare L, Baea K, Reeder JC, Alpers MP, et al. Plasmodium vivax and mixed infections are associated with severe malaria in children: a prospective cohort study from Papua New Guinea. PLoS Med. 2008;5, e127.

3. Price RN, von Seidlein L, Valecha N, Nosten F, Baird JK, White NJ. Global extent of chloroquine-resistant Plasmodium vivax: a systematic review and meta-analysis. Lancet Infect Dis. 2014;14:982-91.

4. White NJ. Determinants of relapse periodicity in Plasmodium vivax malaria. Malar J. 2011;10:297.

5. Collins WE, Jeffery GM. Primaquine resistance in Plasmodium vivax. Am J Trop Med Hyg. 1996;55:243-9.

6. Edgcomb JH, Arnold J, Yount Jr EH, Alving AS, Eichelberger L, Jeffery GM, et al. Primaquine, SN 13272, a new curative agent in vivax malaria; a preliminary report. J Natl Malar Soc. 1950;9:285-92.

7. Krudsood S, Tangpukdee N, Wilairatana P, Phophak N, Baird JK, Brittenham GM, et al. High-dose primaquine regimens against relapse of Plasmodium vivax malaria. Am J Trop Med Hyg. 2008;78:736-40.

8. Bennett JW, Pybus BS, Yadava A, Tosh D, Sousa JC, McCarthy WF, et al. Primaquine failure and cytochrome P-450 2D6 in Plasmodium vivax malaria. N Engl J Med. 2013;369:1381-2.

9. Bolchoz LJ, Morrow JD, Jollow DJ, McMillan DC. Primaquine-induced hemolytic anemia: effect of 6-methoxy-8-hydroxylaminoquinoline on rat erythrocyte sulfhydryl status, membrane lipids, cytoskeletal proteins, and morphology. J Pharmacol Exp Ther. 2002;303:141-8.

10. Dern RJ, Beutler E, Alving AS. The hemolytic effect of primaquine. V. Primaquine sensitivity as a manifestation of a multiple drug sensitivity. J Lab Clin Med. 1955:45:30-9.

11. Beutler E, Duparc S. Glucose-6-phosphate dehydrogenase deficiency and antimalarial drug development. Am J Trop Med Hyg. 2007;77:779-89.

12. George JN, Sears DA, McCurdy PR, Conrad ME. Primaquine sensitivity in Caucasians: hemolytic reactions induced by primaquine in G-6-PD deficient subjects. J Lab Clin Med. 1967;70:80-93.

13. Monteiro WM, Franca GP, Melo GC, Queiroz AL, Brito M, Peixoto HM, et al. Clinical complications of G6PD deficiency in Latin American and Caribbean populations: systematic review and implications for malaria elimination programmes. Malar J. 2014;13:70.

14. Khoo KK. The treatment of malaria in glucose-6-phosphate dehydrogenase deficient patients in Sabah. Ann Trop Med Parasitol. 1981;75:591-5.

15. Ashley EA, Recht J, White NJ. Primaquine: the risks and the benefits. Malar J. 2014;13:418

16. Howes RE, Piel FB, Patil AP, Nyangiri OA, Gething PW, Dewi M, et al. G6PD deficiency prevalence and estimates of affected populations in malaria endemic countries: a geostatistical model-based map. PLoS Med. 2012;9, e1001339.

17. Alving AS, Johnson CF, Tarlov AR, Brewer GJ, Kellermeyer RW, Carson PE. Mitigation of the haemolytic effect of primaquine and enhancement of its action against exoerythrocytic forms of the Chesson strain of Piasmodium vivax by intermittent regimens of drug administration: a preliminary report. Bull World Health Organ. 1960;22:621-31.

18. Clyde DF. Clinical problems associated with the use of primaquine as a tissue schizontocidal and gametocytocidal drug. Bull World Health Organ. 1981;59:391-5

19. Khim N, Benedet C, Kim S, Kheng S, Siv S, Leang R, et al. G6PD deficiency in Plasmodium falciparum and Plasmodium vivax malaria-infected Cambodian patients. Malar J. 2013;12:171

20. Kim S, Nguon C, Guillard B, Duong S, Chy S, Sum S, et al. Performance of the CareStart G6PD deficiency screening test, a point-of-care diagnostic for primaquine therapy screening. PLoS One. 2011;6, e28357.

21. Glucose-6-phosphate dehydrogenase deficiency. WHO Working Group. Bulletin of the World Health Organization. 1989;67:601.

22. Everett WD, Yoshida A, Pearlman E. Hemoglobin E and glucose-6-phosphate deficiency in the Khmer Air Force (Cambodia). Am J Trop Med Hyg. 1977;26:597-601.

23. Severe falciparum malaria. World Health Organization, Communicable Diseases Cluster. Trans R Soc Trop Med Hyg. 2000;94:S1-S90.
24. Hillmen P, Young NS, Schubert J, Brodsky RA, Socie G, Muus P, et al. The complement inhibitor eculizumab in paroxysmal nocturnal hemoglobinuria. N Engl J Med. 2006;355:1233-43.

25. http://rsc.tech-res.com/Document/safetyandpharmacovigilance/DAIDS-AEGrading-Table-v1.0-DEC2004.pdf gradingtable.pdf.

26. Taylor WR, Widjaja H, Basri H, Tjitra E, Ohrt C, Taufik T, et al. Haemoglobin dynamics in Papuan and non-Papuan adults in northeast Papua, Indonesia, with acute, uncomplicated vivax or falciparum malaria. Malar J. 2013;12:209.

27. Akiyoshi T, Saito T, Murase S, Miyazaki M, Murayama N, Yamazaki H, et al. Comparison of the inhibitory profiles of itraconazole and cimetidine in cytochrome P450 3A4 genetic variants. Drug Metab Dispos. 2011;39:724-8.

28. Sansone S, Rottensteiner J, Stocker J, Rosanelli C, Wiedermann CJ. Ciprofloxacin-induced acute haemolytic anaemia in a patient with glucose6-phosphate dehydrogenase Mediterranean deficiency: a case report. Ann Hematol. 2010;89:935-7.

29. Llanos-Cuentas A, Lacerda MV, Rueangweerayut R, Krudsood S, Gupta SK, Kochar SK, et al. Tafenoquine plus chloroquine for the treatment and relapse prevention of Plasmodium vivax malaria (DETECTIVE): a multicentre, doubleblind, randomised, phase 2b dose-selection study. Lancet. 2014;383:1049-58.

30. Lacerda MV, Fragoso SC, Alecrim MG, Alexandre MA, Magalhaes BM, Siqueira AM, et al. Postmortem characterization of patients with clinical diagnosis of Plasmodium vivax malaria: to what extent does this parasite kill? Clin Infect Dis. 2012;55:e67-74.

31. Roca-Feltrer A, Khim N, Kim S, Chy S, Canier L, Kerleguer A, et al. Field trial evaluation of the performances of point-of-care tests for screening G6PD deficiency in Cambodia. PLoS One. 2014;9, e116143.

32. White NJ, Qiao LG, Qi G, Luzzatto L. Rationale for recommending a lower dose of primaquine as a Plasmodium falciparum gametocytocide in populations where G6PD deficiency is common. Malar J. 2012;11:418.

33. Ashley EA, Dhorda M, Fairhurst RM, Amaratunga C, Lim P, Suon S, et al. Spread of artemisinin resistance in Plasmodium falciparum malaria. $N$ Engl J Med. 2014;371:411-23.

34. Pannacciulli I, Tizianello A, Ajmar F, Salvidio E. The course of experimentally induced hemolytic anemia in a primaquine-sensitive Caucasian. A case study. Blood. 1965;25:92-5.

35. Pannacciulli I, Salvidio E, Tizianello A, Parravidino G. Hemolytic effects of standard single dosages of primaquine and chloroquine on G-6-PDdeficient Caucasians. J Lab Clin Med. 1969;74:653-61.

36. Leslie T, Mayan I, Mohammed N, Erasmus P, Kolaczinski J, Whitty CJ, et al. A randomised trial of an eight-week, once weekly primaquine regimen to prevent relapse of Plasmodium vivax in Northwest Frontier Province, Pakistan. PLoS One. 2008;3, e2861.

37. Charoenlarp P, Areekul S, Harinasuta T, Sirivorasarn P. The haemolytic effect of a single dose of $45 \mathrm{mg}$ of primaquine in G-6-PD deficient Thais. J Med Assoc Thai. 1972;55:631-8.

38. Kondrashin A, Baranova AM, Ashley EA, Recht J, White NJ, Sergiev VP. Mass primaquine treatment to eliminate vivax malaria: lessons from the past. Malar J. 2014;13:51.

39. Leslie T, Briceno M, Mayan I, Mohammed N, Klinkenberg E, Sibley CH, et al. The impact of phenotypic and genotypic G6PD deficiency on risk of Plasmodium vivax infection: a case-control study amongst Afghan refugees in Pakistan. PLoS Med. 2010;7, e1000283.

\section{Submit your next manuscript to BioMed Central and take full advantage of:}

- Convenient online submission

- Thorough peer review

- No space constraints or color figure charges

- Immediate publication on acceptance

- Inclusion in PubMed, CAS, Scopus and Google Scholar

- Research which is freely available for redistribution 